\title{
Sticky Information in General Equilibrium
}

\section{Citation}

Mankiw, N. Gregory, and Ricardo Reis. 2007. Sticky information in general equilibrium. Journal of the European Economic Association 5(2-3): 603-613.

\section{Published Version}

http://dx.doi.org/10.1162/jeea.2007.5.2-3.603

\section{Permanent link}

http://nrs.harvard.edu/urn-3:HUL.InstRepos:3415323

\section{Terms of Use}

This article was downloaded from Harvard University's DASH repository, and is made available under the terms and conditions applicable to Other Posted Material, as set forth at http:// nrs.harvard.edu/urn-3:HUL.InstRepos:dash.current.terms-of-use\#LAA

\section{Share Your Story}

The Harvard community has made this article openly available.

Please share how this access benefits you. Submit a story.

Accessibility 


\title{
STICKY INFORMATION \\ IN GENERAL EQUILIBRIUM
}

\author{
N. Gregory Mankiw \\ Harvard University
}

\author{
Ricardo Reis \\ Princeton University
}

\begin{abstract}
This paper develops and analyzes a general-equilibrium model with sticky information. The only rigidity in goods, labor, and financial markets is that agents are inattentive, sporadically updating their information sets, when setting prices, wages, and consumption. After presenting the ingredients of such a model, the paper develops an algorithm to solve this class of models and uses it to study the model's dynamic properties. It then estimates the parameters of the model using U.S. data on five key macroeconomic time series. It finds that information stickiness is present in all markets, and is especially pronounced for consumers and workers. Variance decompositions show that monetary policy and aggregate demand shocks account for most of the variance of inflation, output, and hours. (JEL: E30, E10)
\end{abstract}

\section{Introduction}

Estimation and simulation of medium-sized macroeconometric models has increasingly attracted the attention of economists who study monetary policy and the business cycle. ${ }^{1}$ This paper contributes to that effort by focusing on a model in which sticky information is the key imperfection that causes output to deviate from its long-run classical benchmark. In this otherwise standard dynamic stochastic general equilibrium model, information is updated sporadically by firms setting prices, workers setting wages, and consumers setting the level of spending.

Solution and estimation of a general equilibrium model with sticky information raises several thorny technical issues. We begin this paper by outlining those issues and proposing solutions. Our first contribution is methodological. It consists of two propositions that provide an algorithm that efficiently solves mediumsized sticky-information models, derives their impulse response functions, and calculates their likelihood in a few seconds.

Acknowledgments: We are grateful to Tiago Berriel for excellent research assistance and to Ruchir Agarwal and Mark Watson for useful comments. All of the programs used in this paper are available at our Web sites.

E-mail addresses: Mankiw: ngmankiw@harvard.edu; Reis: rreis@ princeton.edu

1. See, for instance, Smets and Wouters (2003) and Levin et al. (2006). 
We then proceed to estimate the model using five key time series: inflation, output, hours worked, wages, and an interest rate. The second contribution of this paper is to propose, implement, and compare two estimation strategies for the model: maximum likelihood and a Bayesian approach. The two strategies yield similar results.

We thus obtain estimates of how much information stickiness is needed to explain business cycle dynamics. We find that about a fifth of workers and consumers update their information sets every quarter, so the mean information lag for both household members is approximately five quarters. By contrast, firms are estimated to be much better informed when setting prices: About two-thirds update their information set every quarter.

The model also produces an estimated variance decomposition, which shows how much of the variation in each variable is attributable to each of the five shocks in the model. For inflation, more than $80 \%$ of the variance is attributable to the monetary policy shock. For output growth and hours worked, the monetary policy shock is important, but so is the shock to aggregate demand. The other three shocks - to productivity, the goods markup, and the labor markup — are estimated to explain only a small fraction of the variance of inflation, output growth, and hours worked.

\section{The Model of the Economy}

We study a general-equilibrium model with monopolistic competition and no capital accumulation, familiar in the literature on monetary policy. We assume a continuum of households with preferences that are additively separable and isoelastic in consumption and leisure. Households live forever and wish to maximize expected discounted utility while being able to save and borrow by trading bonds between themselves. We think of households as having two members: a worker and a consumer. The workers sell labor to firms in a set of segmented markets for different labor varieties, where each worker is the sole provider of each variety. The consumers buy a continuum of varieties of goods from firms, which they value according to a Dixit-Stiglitz aggregator. There is a continuum of firms, each selling one variety of goods under monopolistic competition. Each firm operates a decreasing returns to scale technology in total labor input, which is a Dixit-Stiglitz aggregate of the different varieties of labor. Finally, monetary policy follows a Taylor rule.

Less common is our assumption on information. There are three agents making decisions in this economy: consumers, workers, and firms. We assume that each period, a fraction $\delta$ of consumers, a fraction $\omega$ of workers, and a fraction $\lambda$ of firms, randomly drawn from their respective populations, obtain new information and calculate their optimal actions. This assumption of sticky information can 
be justified by costs of acquiring, absorbing, and processing information (Reis 2006a, 2006b) or by appealing to epidemiology (Carroll 2003). ${ }^{2}$

We leave for the Appendix (available in the working paper version) the detailed presentation of the model, the definition of an equilibrium, and its loglinearization. Here, we discuss the five key reduced-form relations. The first relation is the Phillips curve or aggregate supply curve:

$$
\begin{aligned}
p_{t}= & \lambda \sum_{j=0}^{\infty}(1-\lambda)^{j} E_{t-j}\left[p_{t}+\frac{\beta\left(w_{t}-p_{t}\right)+(1-\beta) y_{t}-a_{t}}{\beta+v(1-\beta)}\right. \\
& \left.-\frac{\beta v_{t}}{(v-1)[\beta+v(1-\beta)]}\right] .
\end{aligned}
$$

The price level $\left(p_{t}\right)$ depends on past expectations of (a) its current value, (b) real marginal costs, and (c) desired markups. ${ }^{3}$ Marginal costs are higher (i) the higher are the real wages paid to workers $\left(w_{t}-p_{t}\right)$, (ii) the more is produced $\left(y_{t}\right)$ because of decreasing returns to scale $(\beta<1)$, and (iii) the lower is aggregate productivity $\left(a_{t}\right)$. The desired markup falls with the elasticity of substitution across goods varieties $\left(v_{t}\right)$, which we allow to vary randomly over time. Unexpected shocks to any of these three variables only raise prices by $\lambda$ because only this share of price-setters is aware of the news.

The second relation is the IS curve:

$$
y_{t}=\delta \sum_{j=0}^{\infty}(1-\delta)^{j} E_{t-j}\left(y_{\infty}^{n}-\theta R_{t}\right)+g_{t},
$$

where the long-run equilibrium output is $y_{\infty}^{n}=\lim _{i \rightarrow \infty} E_{t}\left[y_{t+i}\right]$ and the long real interest rate is $R_{t}=E_{t}\left[\sum_{j=0}^{\infty}\left(i_{t+j}-\Delta p_{t+1+j}\right)\right]$. Higher expected future output raises wealth and increases spending, whereas higher expected interest rates encourage savings and lower spending. The impact of interest rates on spending depends on the intertemporal elasticity of substitution $\theta$. We denote by $g_{t}$ aggregate demand shocks, which in the model correspond to changes in government spending, but could also be modeled as changes in the relative desire for leisure. The higher is $\delta$, the larger is the share of informed consumers who respond to shocks immediately.

2. The optimal behavior of these inattentive agents and their interaction in markets raise some interesting challenges. We discuss these in Mankiw and Reis (2006).

3. All variables with a $t$ subscript refer to log-linearized values around their non-stochastic steady state. Those without any subscript are fixed parameters and steady state values. 
Next comes the wage curve:

$$
\begin{aligned}
w_{t}= & \omega \sum_{j=0}^{\infty}(1-\omega)^{j} E_{t-j}\left[p_{t}+\frac{\gamma\left(w_{t}-p_{t}\right)}{\gamma+\psi}\right. \\
& \left.+\frac{l_{t}}{\gamma+\psi}+\frac{\psi\left(y_{\infty}^{n}-\theta R_{t}\right)}{\theta(\gamma+\psi)}-\frac{\psi \gamma_{t}}{(\gamma+\psi)(\gamma-1)}\right] .
\end{aligned}
$$

The five determinants of nominal wages are split into the five terms on the righthand side: First, nominal wages rise one-to-one with prices because workers care about real wages. Second, the higher are real wages elsewhere in the economy, the higher is demand for a worker's variety of labor, so the higher the wage she will demand. Third, the more labor is hired $\left(l_{t}\right)$ the better it must be compensated because the marginal disutility of working rises. Fourth, higher wealth discourages work through an income effect, and higher interest rates promote it by giving a larger return on saved earnings today. The product of $\psi$, the Frisch elasticity of labor supply, and $\theta$, the intertemporal elasticity of substitution, determines the strength of this intertemporal labor supply effect. Fifth and finally, if the elasticity of substitution across labor varieties $\left(\gamma_{t}\right)$ rises, workers' desired markup falls so they lower their wage demands. If many workers are informed ( $\omega$ is high), wages are instantly very responsive to changes in these determinants, whereas otherwise wages only respond gradually over time.

The fourth relation is a standard production function,

$$
y_{t}=a_{t}+\beta l_{t},
$$

where $\beta$ measures the extent of decreasing returns to scale from using more labor. The fifth and final relation is the Taylor rule,

$$
i_{t}=\varphi_{y}\left(y_{t}-y_{t}^{n}\right)+\varphi_{p} \Delta p_{t}-\varepsilon_{t},
$$

where $y_{t}-y_{t}^{n}$ is the output gap, or the difference between actual output and its level if all agents were attentive, and $\varepsilon_{t}$ are policy disturbances.

These five equations give the equilibrium values for output, wages, prices, labor, and nominal interest rates as a function of shocks to aggregate productivity growth, aggregate demand, goods markups, labor markups, and monetary policy. We assume that each of these shocks follows an autoregressive process of order 1 with coefficients $\rho_{\Delta a}, \rho_{g}, \rho_{\nu}, \rho_{\gamma}$, and $\rho_{\varepsilon}$, and is subject to innovations $e_{t}^{\Delta a}$, $e_{t}^{g}, e_{t}^{\nu}, e_{t}^{\gamma}$, and $e_{t}^{\varepsilon}$, that are independent and normally distributed with standard deviations $\sigma_{\Delta a}, \sigma_{g}, \sigma_{v}, \sigma_{\gamma}$, and $\sigma_{\varepsilon}$. 


\section{Solving for the Economy's Dynamics}

Our model fits into the general class of linear rational expectations models for which there are several ready-to-use solution algorithms. However, none of them is particularly useful to solve the sticky-information model. The model involves both an infinite number of past expectations of the present through sticky information, as well as present expectations of variables at an infinite number of future dates through intertemporal smoothing. This double infinity implies that the statespace of the model has an infinite dimension, which current algorithms cannot handle. ${ }^{4}$

We have developed a general algorithm that can solve this and much larger general-equilibrium models with sticky information in a few seconds. It is based on the following result, which comes from using a method of undetermined coefficients and exploiting the recursiveness of the model's dynamics:

PROPOSITION 1. Let $s \in S=\{\Delta a, g, v, \gamma, \varepsilon\}$ denote the different shocks. Then $p_{t}=\sum_{s \in S} \sum_{n=0}^{\infty} \hat{p}_{n}(s) e_{t-n}^{s}$, where $\hat{p}_{n}(s)$ is a scalar measuring the impact of shock $s$ at lag $n$ on the price level. The undetermined coefficients solve the second-order difference equation

$$
A_{n+1} \hat{p}_{n+1}(s)-B_{n} \hat{p}_{n}(s)+\varphi_{p} \hat{p}_{n-1}(s)=C_{n}(s) \text { for } n=0,1,2, \ldots
$$

with boundary conditions $\hat{p}_{-1}=0$ and $\lim _{n \rightarrow \infty}\left(\hat{p}_{n}-\hat{p}_{n-1}\right)=0$. The coefficients $A_{n}$ and $B_{n}$ do not depend on the shock, while $C_{n}(s)$ does; all depend on the parameters and are given in the Appendix.

The Appendix describes our algorithm to solve this difference equation and finds, in Corollary 1, the solution for the other variables in the model as a function of the price dynamics.

Figure 1 shows the responses of inflation, the output gap, and labor to onestandard-deviation shocks to monetary policy, aggregate productivity growth, and aggregate demand. ${ }^{5}$ In response to a monetary expansion, output and labor increase as the economy enters a boom. Inflation rises gradually, following the hump-shaped pattern that has been found in empirical work. Noticeably, inflation is more persistent than output, another robust feature of the data that many monetary models have trouble reproducing. The model fits well the facts on how the economy responds to monetary policy shocks.

4. Recently, Wang and Wen (2006) proposed an ingenious method to adapt existing algorithms to solve sticky-information models. We leave a systematic comparison of their method with the one in this paper for future research.

5. The parameters are set at the maximum-likelihood estimates in Table 1, described in the next section. 


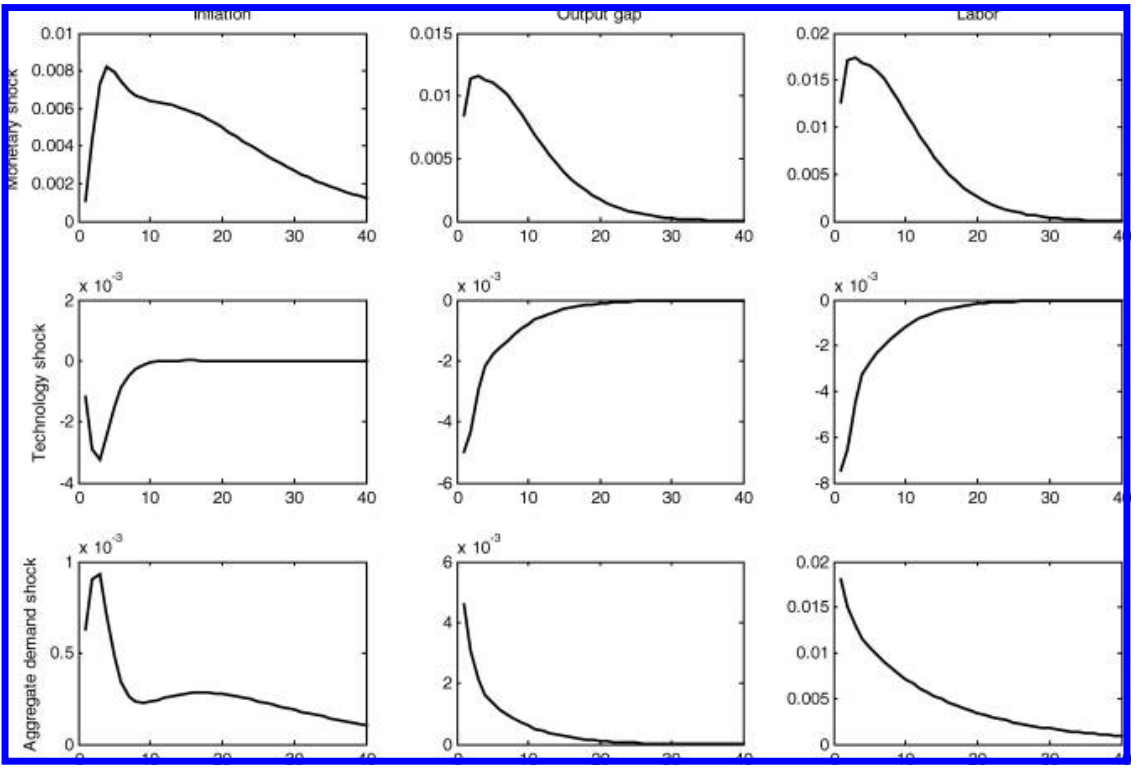

FIGURE 1. Impulse responses to one-standard-deviation shocks.

In response to a positive technological shock, inflation falls but converges rapidly to its previous level. Interestingly, positive productivity shocks in this economy lead to recessions, just as in sticky price models (Galí 1999). However, this is not a robust feature of the sticky-information model: for different parameter values, we can get a boom following a technological improvement. Finally, a positive innovation to aggregate demand raises inflation, output, and labor.

\section{Estimating the Model}

We use U.S. quarterly data from 1954:3 to 2006:1 for the non-farm business sector. We measure wages using the total compensation per hour and labor input using total hours. We divide output and hours by the total civilian non-institutional population and deflate nominal variables using the implicit price deflator for the nonfarm business sector. Changes in the log of this deflator are our measure of inflation, and the effective federal funds rate measures the nominal interest rate.

Using these data, we build series for de-meaned inflation, output growth, nominal interest rates, real wage growth, and hours. These are our observables, collected in the vector $x_{t}=\left(\Delta p_{t}, \Delta y_{t}, l_{t}, i_{t}, \Delta\left(w_{t}-p_{t}\right)\right)^{\prime}$. The sticky-information general-equilibrium model implies that $x_{t}=\sum_{i=0}^{\infty} \Phi_{i} e_{t-i}$, where $e_{t}$ is the vector of shocks $\left(e_{t}^{\varepsilon}, e_{t}^{\Delta a}, e_{t}^{g}, e_{t}^{v}, e_{t}^{\gamma}\right)^{\prime}$ and the $\Phi_{i}$ are $5 \times 5$ matrices of coefficients, found 
in Proposition 1 and Corollary 1. The question we ask in this section is how to estimate the vector of parameters of the model using these data.

We estimate our model using both maximum likelihood and Bayesian methods. The key input into these methods is the likelihood function, which in standard dynamic models with a state-space solution can be evaluated using the Kalman filter. The solution of the model using Proposition 1 does not have a convenient state-space representation, so we use instead the following result.

PROPOSITION 2. Given a sample of data of length $T$, let $X$ be the $5 T \times 1$ vector that vertically stacks the $x_{t}$ and let $\Omega$ be the $5 T \times 5 N$ matrix

$$
\left[\begin{array}{ccccccccc}
\Phi_{0} & \Phi_{1} & \Phi_{2} & \ldots & \ldots & \ldots & \Phi_{N-3} & \Phi_{N-2} & \Phi_{N-1} \\
\Phi_{1} & \Phi_{0} & \Phi_{1} & \ldots & \ldots & \ldots & \Phi_{N-4} & \Phi_{N-3} & \Phi_{N-2} \\
\Phi_{2} & \Phi_{1} & \Phi_{0} & \cdots & \ldots & \ldots & \Phi_{N-5} & \Phi_{N-4} & \Phi_{N-3} \\
\vdots & \vdots & \vdots & \vdots & \vdots & \vdots & \vdots & \vdots & \vdots \\
\Phi_{T-1} & \Phi_{T-2} & \cdots & \Phi_{1} & \Phi_{0} & \Phi_{1} & \cdots & \Phi_{N-T-1} & \Phi_{N-T}
\end{array}\right] .
$$

Finally, let $\Sigma$ be a diagonal matrix with $\left(\sigma_{\varepsilon}^{2}, \sigma_{\Delta a}^{2}, \sigma_{g}^{2}, \sigma_{v}^{2}, \sigma_{\gamma}^{2}\right)$ in the diagonal and $I_{N}$ be an identity matrix of size $N$. The log-likelihood function is

$$
\mathscr{L}=-2.5 T \ln (2 \pi)-0.5 \ln \left|\Omega\left(I_{N} \otimes \Sigma\right) \Omega^{\prime}\right|-0.5 X^{\prime}\left(\Omega\left(I_{N} \otimes \Sigma\right) \Omega^{\prime}\right)^{-1} X .
$$

The main difficulty with evaluating this expression is that inverting the large $5 T \times 5 T$ matrix $\Omega\left(I_{N} \otimes \Sigma\right) \Omega^{\prime}$ is both slow and subject to potentially large numerical errors. The Appendix shows how to evaluate (7) without inverting this matrix by instead solving a recursive linear system of equations. This provides an algorithm to evaluate the log-likelihood function quickly and reliably.

Turning to estimation, we set the value of 9 out of the 20 parameters. Namely, we set the intertemporal elasticity of substitution to 1 (the King-Plosser-Rebelo, 1988, utility function) to guarantee that hours are stationary, the Frisch elasticity of labor supply to 4 , and the labor share to $2 / 3$. Using the production function, we can then measure the aggregate productivity shocks exactly, and estimate that $\rho_{\Delta a}=0.350$ and $\sigma_{\Delta a}=0.010$. We set $\varphi_{y}=0.33$ and $\varphi_{p}=1.24$ to match Rudebusch's (2002) estimates of the Taylor rule, and using these we estimate that $\rho_{\varepsilon}=0.918$ and $\sigma_{\varepsilon}=0.012$.

We start our estimation of the model by finding the set of parameters that maximize the likelihood function. Table 1 presents the estimates. Curiously, we estimate a value for the elasticity of substitution between goods that is higher and a value for the elasticity of substitution between labor that is lower than what is typically assumed. The implied price markup is only $3 \%$ and the implied wage markup is $31 \%$, whereas usually these are calibrated to values between $5 \%$ and $20 \%$. A second feature to note is that most estimates are quite precise, with tight confidence intervals. 


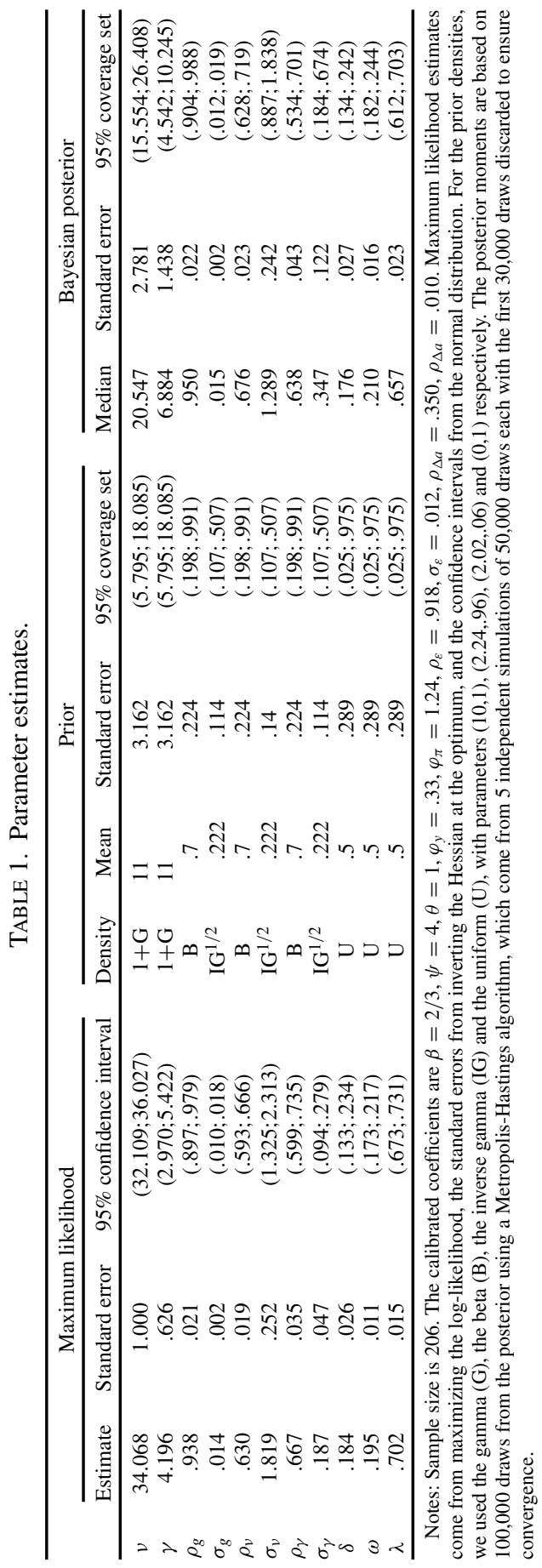


Our main focus of interest are the measures of information stickiness. We estimate that firms are relatively attentive, updating their information about every 4 months, whereas consumers and workers are quite inattentive, only updating their plans about every 16 months. We test the null hypothesis that both members of a household, the consumer and the worker, update their information at the same time. The likelihood ratio statistic is 0.089 , which has a $p$ value of 0.23 in the $\chi_{1}^{2}$ distribution. The data do not reject this plausible hypothesis.

Table 2 presents the variance decompositions associated with these estimates. Noticeably, the variance of inflation, output, and hours is almost entirely accounted for solely by monetary and aggregate demand shocks. Shocks to productivity and price markups are relatively unimportant for these three variables, but play a role on the fluctuations of interest rates and real wages. Wage markups

TABLE 2. Variance decompositions.

\begin{tabular}{lccccc}
\hline \multicolumn{7}{c}{ Maximum likelihood estimates and 95\% confidence intervals } \\
\hline \multicolumn{5}{c}{ Shock } \\
Variable & Monetary & Aggregate & Aggregate & Goods & Labor \\
productivity & demand & markup & markup \\
\hline Inflation & .896 & .028 & .004 & .070 & .003 \\
& $(.826 ; .937)$ & $(.019 ; .041)$ & $(.002 ; .009)$ & $(.033 ; .130)$ & $(.001 ; .006)$ \\
Output growth & .247 & .153 & .436 & .101 & .064 \\
& $(.171 ; .320)$ & $(.115 ; .198)$ & $(.257 ; .610)$ & $(.040 ; .185)$ & $(.024 ; .132)$ \\
Hours & .551 & .032 & .336 & .041 & .041 \\
Interest rate & $(.319 ; .663)$ & $(.014 ; .067)$ & $(.179 ; .612)$ & $(.012 ; .084)$ & $(.010 ; .116)$ \\
& .506 & .066 & .017 & .295 & .117 \\
Wage growth & $(.352 ; .646)$ & $(.048 ; .089)$ & $(.008 ; .031)$ & $(.163 ; .438)$ & $(.053 ; .200)$ \\
& .183 & .262 & .016 & .479 & .061 \\
& $(.136 ; .244)$ & $(.195 ; .360)$ & $(.007 ; .033)$ & $(.300 ; .605)$ & $(.027 ; .099)$ \\
\hline
\end{tabular}

Bayesian median estimates and $95 \%$ credible sets

\begin{tabular}{lccccc}
\hline \multicolumn{5}{c}{ Shock } \\
\hline Variable & Monetary & $\begin{array}{c}\text { Aggregate } \\
\text { productivity }\end{array}$ & $\begin{array}{c}\text { Aggregate } \\
\text { demand }\end{array}$ & $\begin{array}{c}\text { Goods } \\
\text { markup }\end{array}$ & $\begin{array}{c}\text { Labor } \\
\text { markup }\end{array}$ \\
\hline Inflation & .835 & .028 & .005 & .129 & .002 \\
& $(.717 ; .906)$ & $(.019 ; .040)$ & $(.003 ; .010)$ & $(.066 ; .242)$ & $(.001 ; .004)$ \\
Output growth & .213 & .133 & .446 & .150 & .048 \\
& $(.155 ; .274)$ & $(.101 ; .164)$ & $(.309 ; .590)$ & $(.080 ; .263)$ & $(.021 ; .107)$ \\
Hours & .469 & .028 & .398 & .063 & .025 \\
Interest rate & $. .237 ; .603)$ & $(.010 ; .057)$ & $(.238 ; .703)$ & $(.023 ; .144)$ & $(.006 ; .076)$ \\
& .408 & .057 & .016 & .416 & .093 \\
Wage growth & $(.251 ; .569)$ & $(.039 ; .077)$ & $(.010 ; .027)$ & $(.266 ; .585)$ & $(.043 ; .188)$ \\
& .093 & .192 & .035 & .663 & .035 \\
& $(.053 ; .146)$ & $(.125 ; .271)$ & $(.008 ; .027)$ & $(.514 ; .786)$ & $(.017 ; .070)$ \\
\hline
\end{tabular}

Notes: The maximum likelihood variance decomposition uses the MLE parameter estimates, and the confidence interval values are the $2.5 \%$ and $97.5 \%$ percentiles of 1,000 draws from a multivariate normal with moments set at the MLE estimates. Bayesian estimates are the median, $2.5 \%$ and $97.5 \%$ percentiles cell-by-cell using 100,000 draws from the posterior density. 
are on average large, but their fluctuations explain little of the variance of any of the variables.

Next we estimate our model using Bayesian methods instead. We see the main virtue of these methods as allowing us, through the priors, to focus on an area of the parameter space that we are particularly interested in. In our case, this area corresponds to the typical calibrations of these models. For instance, we pick priors for the average substitutability of goods and labor that imply average markups that are with $95 \%$ confidence between $6 \%$ and $21 \%$, the values commonly assumed in the literature. For the parameters of inattentiveness, we instead opt for a flat prior in order to impose as little as possible on the data. The priors for the correlation and the variance of shocks are similar to those on the literature, although they are more diffuse than usual.

Table 1 contains the results, which turn out to be similar to the maximumlikelihood results. As expected, the difference between the markups on goods and labor is not as extreme as before, as our prior heavily penalizes those extreme results. Also as expected, our diffuse priors lead to wider credible sets. However, the estimates of inattentiveness are relatively similar: Consumers and workers update their information every 5 to 6 quarters, whereas firms update every 1.5 quarters. Table 2 shows the variance decompositions using these Bayesian estimates. These are similar to the maximum-likelihood conclusions, with the exception of shocks to goods markups, which now account for a larger share of the variance of all variables.

\section{Conclusion}

In Mankiw and Reis (2002), we proposed a new way to model sluggish macroeconomic adjustment. In this paper we have explored how this approach can be used in an empirical dynamic stochastic general equilibrium model.

One lesson from our estimation (and also emphasized in Mankiw and Reis [2006]) is that information stickiness is pervasive: It applies to firms, workers, and consumers. Some recent research has estimated empirical dynamic stochastic general equilibrium models with sticky information on the part of firms, assuming fully informed workers and consumers. ${ }^{6}$ Our results suggest that these models were misspecified; this misspecification can potentially explain reported poor fits of the models. Although more work is needed before reaching a final verdict, we believe the assumption of sticky information remains a promising tool for applied macroeconomists.

6. The working paper version of this article discusses this research. 


\section{References}

Carroll, Christopher D. (2003). "Macroeconomic Expectations of Households and Professional Forecasters." Quarterly Journal of Economics, 118, 269-298.

Galí, Jordi (1999). "Technology, Employment, and the Business Cycle: Do Technology Shocks Explain Aggregate Fluctuations?” American Economic Review, 89(1), 249-271.

King, Robert G., Charles Plosser, and Sergio T. Rebelo (1988). "Production, Growth and Business Cycles. I. The Basic Neoclassical Model." Journal of Monetary Economics, 21, 195-232.

Levin, Andrew T., Alexei Onatski, John C. Williams, and Noah Williams (2006). "Monetary Policy Under Uncertainty in Micro-Founded Macroeconometric Models." In NBER Macroeconomics Annual 2005, edited by Mark Gertler and Kenneth Rogoff. MIT Press.

Mankiw, N. Gregory, and Ricardo Reis (2002). "Sticky Information versus Sticky Prices: A Proposal to Replace the New Keynesian Phillips Curve." Ouarterly Journal of Economics, 117(4), 1295-1328.

Mankiw, N. Gregory, and Ricardo Reis (2006). "Pervasive Stickiness." American Economic Review, 96(2), 164-169.

Reis, Ricardo (2006a). “Inattentive Consumers.” Journal of Monetarv Economics, 53(8), 17611800.

Reis, Ricardo (2006b). "Inattentive Producers." Review of Economic Studies, 73(3), 793-821.

Rudebusch, Glenn D. (2002). "Term Structure Evidence on Interest Rate Smoothing and Monetary Policy Inertia." Journal of Monetarv Economics, 49(6), 1161-1187.

Smets, Frank, and Raf Wouters (2003). "An Estimated Stochastic Dynamic General Equilibrium Model of the Euro Area." Journal of the European Economic Association, 1(5), 1123-1175.

Wang, Pengfei, and Yi Wen (2006). "Solving Linear Difference Systems with Lagged Expectations by a Method of Undetermined Coefficients." Working paper, Federal Reserve Bank of Saint Louis. 
This article has been cited by:

1. Benjamin D. Keen. 2009. THE SIGNAL EXTRACTION PROBLEM REVISITED: A NOTE ON ITS IMPACT ON A MODEL OF MONETARY POLICY. Macroeconomic Dynamics 1. [CrossRef]

2. Ricardo Reis. 2009. Optimal Monetary Policy Rules in an Estimated Sticky-Information Model. American Economic Journal: Macroeconomics 1:2, 1-28. [CrossRef]

3. Gabriel Galand. 2009. The Neutrality of Money Revisited with a Bottom-Up Approach: Decentralisation, Limited Information and Bounded Rationality. Computational Economics 33:4, 337-360. [CrossRef]

4. William A. Branch, John Carlson, George W. Evans, Bruce McGough. 2009. Monetary Policy, Endogenous Inattention and the Volatility Trade-off*. The Economic Journal 119:534, 123-157. [CrossRef] 